\title{
Study on Corrosion Resistance of Anodized 6463 Aluminum Alloy as Construction Material in 3.5\% Sodium Chloride Solution
}

\author{
LingFeng Ji, JiuQuan Chen ${ }^{*}$, RuiHong Zhang \\ Hebei Construction Material Vocational and Technical College, Qinhuangdao, 066004, China \\ *E-mail: chenconstruction@163.com
}

Received: 7 September 2021 / Accepted: 9 October 2021 / Published: 10 November 2021

\begin{abstract}
6463 aluminum alloys used for construction materials were anodized from the solution mixed with sulfuric acid and boric acid to improve mechanical and anticorrosion properties. The influences of current densities on hardness, roughness, thickness, corrosion resistance and surface morphology of anodized aluminum were investigated. It is found out that the oxidation process of aluminum alloy is accompanied by the formation and dissolution of alumina. The outer layer of anodized aluminum is porous and the inner layer is a barrier layer with high impedance. Higher current density will get anodized aluminum with larger surface roughness. With the increase of current density, the thickness and hardness of anodized aluminum increase gradually and then decrease. Anodized aluminum obtained at the condition of $2 \mathrm{~A} / \mathrm{dm}^{2}$ shows even and porous structure resulting in higher hardness and optimal corrosion resistance performance with minimum corrosion current density equal to $4.365 \mu \mathrm{A} / \mathrm{cm}^{2}$.
\end{abstract}

Keywords: 6463 aluminum alloys; construction materials; anodizing; Corrosion resistance;

\section{$\underline{\text { FULL TEXT }}$}

(C) 2021 The Authors. Published by ESG (www.electrochemsci.org). This article is an open access article distributed under the terms and conditions of the Creative Commons Attribution license (http://creativecommons.org/licenses/by/4.0/). 